\title{
PROBABILITY BASED DESIGN OF PUNCHING SHEAR RESISTANCE OF COLUMN TO SLAB CONNECTIONS
}

\author{
Povilas VAINIŪNAS, Remigijus ŠALNA, Dainius ŠAKINIS \\ Vilnius Gediminas Technical University, Department of Reinforced Concrete and Masonry Structures, \\ Sauletekio al. 11, 10223 Vilnius, Lithuania
}

Received 20 Nov 2014; accepted 13 Mar 2015

\begin{abstract}
The paper analyzes the dependence of punching shear strength reliability index $\beta$, calculated according to EN 1992-1-1:2004 (2004) and STR 2.05.05:2005 (2005) in reinforced concrete floor slab-to-column joint on the values of random factors. The paper deals with theoretical research of the influence of independent random variables, such us the value of the characteristic compressive strength $f_{\mathrm{ck}}$ of concrete, the area $A_{\mathrm{s}}$ of the longitudinal reinforcement, effective cross-section depth $d$ and the ratio of the self-weight and the effective load on the value of the reliability index $\beta$. The paper presents experimental results of reinforced concrete slabs with different longitudinal reinforcement ratio $\rho$ subjected to a concentrated load. It was determined that when the effective load makes around $50 \%$ of the construction self-weight load, i.e. $G_{\mathrm{k}} / Q_{\mathrm{k}}=2$ and when minimal variation coefficient estimates are taken (for concrete strength $\delta f_{c}=0.1$, for effective depth $\delta d=0,1$ and for the area of longitudinal reinforcement cross-section $\delta A_{\mathrm{s}}=0.05$ or $\delta A_{\mathrm{s}}=0.075$ and when $G_{\mathrm{k}}=Q_{\mathrm{k}}$ i.e. $G_{\mathrm{k}} / Q_{\mathrm{k}}=1$ where $\delta f_{c}=0.1, \delta d=0.1$ and $\delta A_{\mathrm{s}}=0.05$ ) the reliability index $\beta$ of the analyzed slabs calculated according to EN 1992-1-1:2004 (2004) as well as $\beta$ calculated according to STR 2.05.05:2005 (2005), is bigger than EN 1990:2002 (2002) recommendation for the minimum value of reliability index -3.8 for RC2 construction reliability class ultimate. In other cases the reliability index $\beta$ is close to 3.8 or much smaller than 3.8 .
\end{abstract}

Keywords: punching shear strength of reinforced concrete slabs, critical perimeter, longitudinal reinforcement ratio $\rho$, reliability index $\beta$, coefficient of variation.

\section{Introduction}

Recently there have been a lot of structures of multistorey buildings with reinforced concrete monolithic flat slabs. Design of such reinforced concrete slabs, their depth, their class and the amount of reinforcement are usually determined by the bending moment caused by external forces at a respective normal section. When slab parameters of bending moment effects are calculated, punching shear strength in the slab to column connection is examined. Due to complicated state of stress in this area that is difficult to predict, there is still no single approach how to calculate punching shear strength of a slab. Design codes of European Union, USA, Britain, Canada, Australia and Lithuania reinforced concrete construction design use different approaches to calculating punching shear strength.

Scientists of many countries have analyzed and recommended to improve the codes and standards applied for designing punching shear strength. European standard EN1992-1-1:2004 (2004), Lithuanian regulations STR 2.05.05:2005 (2005), American code ACI 318-05 (2005) and the Australian standard AS 3600-2009 (2009) require to consider the influence of prestressing when calculating the punching shear strength of a slab whereas ACI 318-05 (2005) and the British standard BS 8110 (1997) require to consider the influence of the bending moment. The European standard EN 1992-1-1:2004 (2004) and STR 2.05.05:2005 (2005), additionally to the influence of prestressing, also require to consider the factor of longitudinal reinforcement in the tension zone. Different theoretical punching shear pyramid outer surface inclination angle $\theta$ and at the same time the distance from the surface of the column to the critical perimeter given in design codes of different countries significantly influence the calculation results. In EN1992-1-1:2004 (2004) this angle is defined to be $26.6^{\circ}$; BS 8110 (1997), DIN 1045-1(07/02) (2002), and STR 2.05.05:2005 (2005) - 33.7 $7^{\circ}$; ACI 318-05 (2005), Canadian CSA-A23.3-04 (2004), AS 3600-2009 (2009), Model Code MC 2010 (2012) and the SNiP 2.03.01-84 (1984) $-45^{\circ}$. If a different inclination angle is taken, the length of the critical perimeter is calculated at a different distance from the column. According to EN 1992-1-1:2004 (2004), the critical perimeter is calculated at $2 d$ distance from the edge of the column, according to Lithuanian

Corresponding author: Remigijus Šalna

E-mail:Remigijus.Salna@vgtu.lt 
codes - the critical perimeter is calculated at $1.5 d$ distance from the edge of the column, whereas according to ACI 318-05 (2005), MC 2010 (2010) - at $d / 2$ distance from the column (Fig. 1).

Calculations of punching shear strength according to different methodologies are given below.

European standard EN 1992-1-1:2004 (2004):

$$
\begin{gathered}
V_{\mathrm{Rd}, \mathrm{c}}=v_{\mathrm{Rd}, \mathrm{c}} d u_{1} ; \\
v_{\mathrm{Rd}, \mathrm{c}}=C_{\mathrm{Rd}, \mathrm{c}} k\left(100 \rho_{1} f_{\mathrm{ck}}\right)^{1 / 3}-k_{1} \sigma_{\mathrm{cp}} \geq\left(v_{\min }+k_{1} \sigma_{\mathrm{cp}}\right) .
\end{gathered}
$$

Technical Regulation of Construction of Lithuania STR 2.05.05:2005 (2005):

$$
\begin{gathered}
V_{\mathrm{Rd}, \mathrm{c}}=v_{\mathrm{Rd}, \mathrm{c}} d u_{1} ; \\
\boldsymbol{v}_{\mathrm{Rd}, \mathrm{c}}=\frac{0.18}{\gamma_{\mathrm{c}}} k\left(100 \rho f_{\mathrm{ck}}\right)^{1 / 3}- \\
0.10 \sigma_{\mathrm{cp}} \leq\left(0.4 f_{\mathrm{ctd}}-0.10 \sigma_{\mathrm{cp}}\right) ;
\end{gathered}
$$

In equations of both normative documents $f_{\mathrm{ck}}$ and $f_{\text {ctd }}$ are in MPa.

$$
\begin{aligned}
& k=1+\sqrt{\frac{200}{d}} \leq 2.0 ; \\
& q=\sqrt{9_{\mathrm{y}} \cdot \rho_{\mathrm{z}}} \leq 0.02,
\end{aligned}
$$

where: $\rho_{\mathrm{ly}}, \rho_{\mathrm{lz}}-$ reinforcement ratios along $y$ and $z$ axes respectively; $\rho_{\mathrm{ly}}$ and $\rho_{\mathrm{lz}}$ are calculated for the section whose area is equal to the width of the column adding $3 d$ to every size of the column:

$$
\sigma_{c p}=\left(\sigma_{c y}+\sigma_{c z}\right) / 2
$$

where: $\sigma_{\mathrm{cy}}, \sigma_{\mathrm{cz}}-$ normal stresses in concrete at the dangerous section, respectively $y$ and $z$ along the axes (MPa), in case of compression, the sign of minus is taken.

It is recommended in EN 1992-1-1:2004 (2004) to take $0.18 / \gamma_{c}$ for $C_{\mathrm{Rd}, \mathrm{c}}$ and $k_{1}=0.10$. Different scientists (Ngo 2001; Menétrey 2002; Theodorakopoulos, Swamy 2002; Vainiūnas 2006) performed a comparative analysis of the values of punching shear strength in reinforced concrete slabs calculated according to differ-

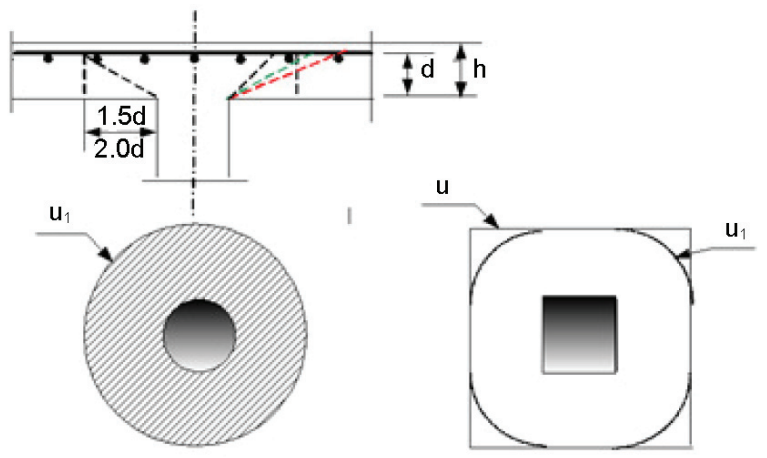

Fig. 1. Principal scheme of calculating punching shear ent design standards with the experimental and numerical experiments. The authors found out that, additionally to concrete shear stresses at the critical section, the biggest influence on the punching shear strength of a slab is attributed to the ratio $\rho$ of longitudinal reinforcement. Research shows that increasing of the ratio of longitudinal reinforcement changes the inclination angle $\theta$ of the external surface of the pyramid under punching shear at the same time changing the distance of the critical section from the surface of the column. If the coefficient $\rho$ of longitudinal reinforcement was close to zero (e.g. in a deep foundation under a column), $\theta$ would be $45^{\circ}$. If $\rho$ increases, $\theta$ decreases and, as a result of this, the distance of the critical section from the surface of the column increases, the length of the critical perimeter increases and at the same time the punching shear strength resistance strength increases. Zabulionis et al. (2006) performed a statistical analysis of the calculation methods provided in design codes for slab-to-column connection without transverse reinforcement. It was determined that EC 2 (EN 1992-1-1:2004 2004) calculation methodology is the most precise in describing punching shear strength in a slab, also, that ACI 318-05 (2005) calculation methodology, which does not evaluate the ratio of $\rho$ longitudinal reinforcement, does not bring in a big calculating error in calculating the punching shear strength of a slab.

Albrecht (2002), Matthys and Taerwe (2000), Muttoni (2008), Ruiz and Muttoni (2009), Guandalini et al. (2009), Rizk et al. (2011) while comparing different calculation methods provided in design codes of different countries with the experimental research made a parallel analysis of the dependence of punching shear strength of slabs on the longitudinal and transverse reinforcement, whereas Carvalho et al. (2011), Faria et al. (2012) also analyzed the influence of advance prepressing.

Scientists of Vilnius Gediminas Technical University have also conducted experimental research to investigate the influence of longitudinal reinforcement ratio $\rho$ on the punching shear strength of a reinforced concrete slab, to define the distance of the critical section from the surface of the column. The results of the experiment were published in the work of Šakinis and Vainiūnas (2009).

Besides, most of different design codes, additionally to the methodology of partial factors (PF), also allows probability-based structural design which is very actual in recent research (Gardner 2011; Soubra et al. 2010; He et al. 2012; Głodkowska, Kobaka 2012; Kong et al. 2013). This is a design method which directly calculates the reliability of structure (or the index $\beta$ of reliability corresponding to it), which is compared to the regulated standardized value (usually $\beta_{n}$ ). The specifics of this method is that while calculating the reliability index of a structure it not only considers the systemic and random errors of the above mentioned methods, but it also applies the values of the non-determined function arguments which are considered to be random values distributed according to a certain law (usually Gauss's). 
It should be noted that in some design codes statistical parameters (arithmetic means and variation coefficients) which are applied to arguments may be applied either from a standardized set or from the one determined in an experimental way. It obviously illustrates that all aforementioned factors, i.e. model errors, statistical parameters of distributions applied to arguments (arithmetic means and variation coefficients), as well as the method of their identification will have a significant influence in calculating the reliability index of a construction. It is, therefore, relevant to perform a comparative analysis of the dependence of calculating the punching shear reliability index $\beta$ of the joint between reinforced concrete floor slabs and a column according to EN 1992-1-1:2004 (2004) and STR 2.05.05:2005 (2005) from different random factor values and determine the most important factors that have an impact on the difference of the results.

\section{Research methods and results}

Five series of specimens were manufactured and tested (10 slabs). During the testing the whole contour of the slab was supported on a stiff steel beam (Fig. 2). The loading of the slab all the way to failure by punching shear was increased in stages $10 \mathrm{kN}$. The dimensions of the specimens were $2135 \times 2135 \times 140 \mathrm{~mm}$, the dimensions of the column head were $200 \times 200 \times 200 \mathrm{~mm}$ (Fig. 3). The longitudinal reinforcement ratio $\rho=0.449 \ldots 1.90 \%$, the diameter of reinforcement bars $8 \ldots 16 \mathrm{~mm}$, reinforcement strength class S400 according to STR 2.05.05:2005 (2005), the spacing of bars $-100 \mathrm{~mm}$ (Fig. 3). The protective layer of concrete of longitudinal reinforcement in all slabs was $20 \mathrm{~mm}$. The compressive cubic strength of concrete $f_{c, \text { cube }}=33,4 \ldots 46.6 \mathrm{MPa}$. The compressive cube strength of concrete was determined by testing standard cubes of $150 \times 150 \times 150 \mathrm{~mm}$, the sample quantity -8 items. Geometrical and mechanical parameters of the slabs as well as the ultimate force are presented in Table 1.

A typical slab failure mode is presented in Figure 4. The detailed data of the experimental programme is presented in Šakinis and Vainiūnas (2009).
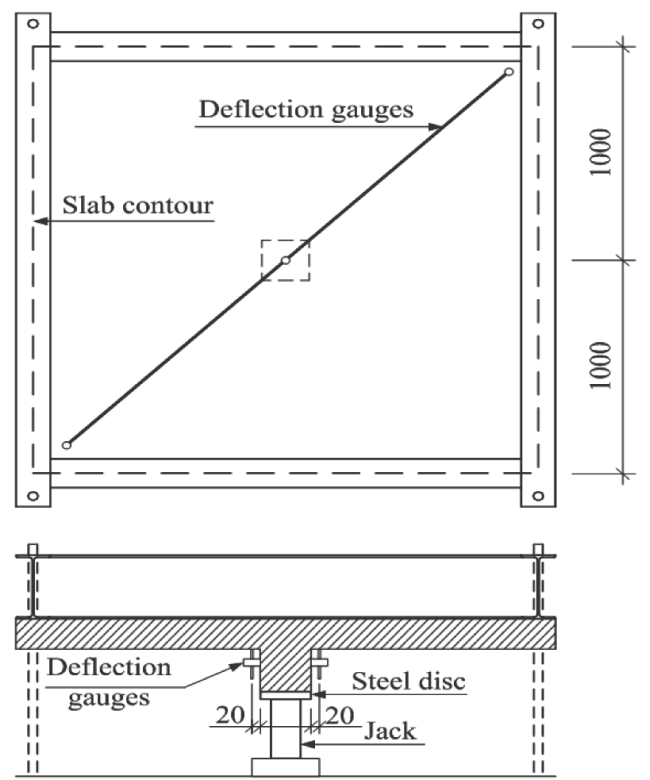

Fig. 2. Slab testing scheme
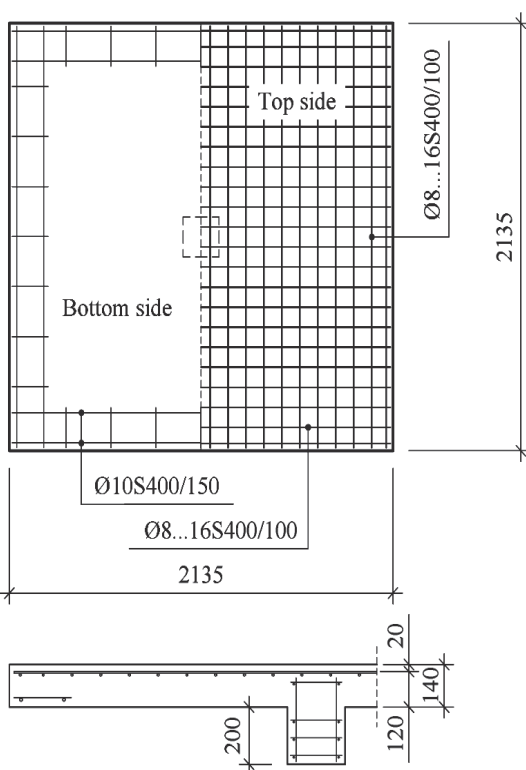

Fig. 3. Reinforcement of a slab

Table 1. Geometrical, mechanical parameters and failure force

\begin{tabular}{c|c|c|c|c|c|c|c}
\hline Slab No. & $h(\mathrm{~mm})$ & $d(\mathrm{~mm})$ & $\rho(\%)$ & $f_{\text {cm }}(\mathrm{MPa})$ & $V_{\text {exp }}(\mathrm{kN})$ & $V_{\text {calc, EN }}(\mathrm{kN})$ & $V_{\text {calc,STR }}(\mathrm{kN})$ \\
PP-04.1 & 140 & 112 & 0.449 & 44.4 & 325.1 & 241.3 & 202.9 \\
PP-04.2 & 140 & 112 & 0.449 & 44.4 & 331.8 & & \\
PP-07.1 & 140 & 110 & 0.718 & 39.2 & 295.1 & 262.9 & 22.3 \\
PP-07.2 & 140 & 110 & 0.718 & 39.2 & 372.7 & & \\
PP-10.1 & 140 & 108 & 1.000 & 46.6 & 374.0 & 301.8 & 254.3 \\
PP-10.2 & 140 & 108 & 1.000 & 46.6 & 402.9 & & \\
PP-15.1 & 140 & 106 & 1.500 & 34.0 & 374.4 & 301.7 & 254.6 \\
PP-15.2 & 140 & 106 & 1.500 & 34.0 & 401.8 & & \\
PP-20.1 & 140 & 104 & 1.900 & 33.4 & 446.4 & 314.7 & 268.5 \\
PP-20.2 & 140 & 104 & 1.900 & 33.4 & 436.0 & & \\
\hline
\end{tabular}




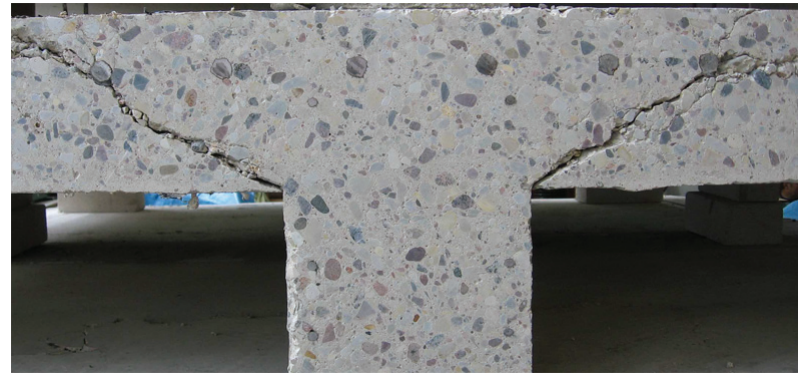

Fig. 4. Typical slab failure mode

\section{Theoretical researches of reliability}

Information Appendix $\mathrm{B}$ of the European standard EN 1990:2002 (2002) and Appendix 3 of the Lithuanian regulations STR 2.05.03:2003 (2003) are used to ensure the management of the reliability of building structures. According to them, there are three classes of buildings $(\mathrm{CC} 1, \mathrm{CC} 2$ and $\mathrm{CC} 3)$ as well as 3 reliability classes matching them which are classified according to the consequences of structural failure or serviceability as well as the hazard they cause. Reliability classes of structures are recommended to be defined by the reliability index $\beta$. The lowest recommended values of the reliability index $\beta$ are given in Table B.2 of EN 1990:2002 (2002). The lowest value of $\beta=3.8$ for the reference period of 50 years for residential, office and public buildings whose collapsing consequences are averagely severe.

The ratio of the reliability index $\beta$ with the probability of structural failure (JCSS code (2000), Eqn (C.5)) is:

$$
\beta=-\Phi-1\left(P_{f}\right)=\Phi-1\left(1-P_{s}\right)
$$

The construction failure probability (EN 1990:2002 2002):

$$
P_{f}=\operatorname{Prob}(\mathrm{g} \leq 0)=\Phi(-\beta),
$$

where: $P_{f}$ - failure probability; $P_{s}-$ survival probability; $g$ - resistance reserve function, (when $g>0$, the construction is supposed for survival, when $g \leq 0$, it is supposed to fail); $g=R-E$; respectively $R$ - construction resistance, $E$ - random variables of an acting effects.

If $g$ is distributed according to the Gaussian law:

$$
\beta=\mu_{g} / \sigma_{g} .
$$

From here $\mu_{g}-\beta_{\text {бg }}=0$, and $P_{f}=\operatorname{Prob}(g \leq 0)=\operatorname{Prob}(g \leq$ $\left.\mu_{\mathrm{g}}-\beta_{\sigma_{\mathrm{g}}}\right) . \mu_{\mathrm{g}}-g$ average value, $\sigma_{\mathrm{g}}-$ standard deviation.

By allying the design values of effect and resistance, calculation is considered to be finished if the critical states are not reached. This condition can be expressed by:

$$
E_{\mathrm{d}}<R_{\mathrm{d}}
$$

The main independent random variables in calculating the reliability index $\beta$ of the punching shear strength of a slab are: $f_{\mathrm{ck}}$ - characteristic compressive strength of concrete, $A_{\mathrm{s}}$ - the area of the cross-section of longitudinal reinforcement and $d$ - the effective depth of the cross-section.

According to Eqns (3) and (4), the characteristic punching shear strength of a slab can be calculated in the following way:

$$
V_{\mathrm{Rc}}=0.18\left(1+(200 / d)^{1 / 2}\right)\left(100\left(A_{\mathrm{s}} / b d\right) f_{\mathrm{ck}}\right)^{1 / 3} d u_{1} .
$$

When $d \leq 200,\left(1+(200 / d)^{1 / 2}\right)$ the equal of 2 is taken, also $b$ is taken as equal to one unit of length, and $u_{1}=4 c+4 \pi d$, when $c_{1}=c_{2}=c$ and $u_{1}$ is calculated at a $2 d$ distance from the column face (EN 1992-1-1:2004 2004):

$$
V_{\mathrm{Rc}}=6.684\left(A_{s} f_{\mathrm{ck}}\right)^{1 / 3}\left(c d^{2 / 3}+\pi d^{5 / 3}\right) .
$$

When $u_{1}$ is calculated at a $1.5 \mathrm{~d}$ distance from the surface of the column (STR 2.05.05:2005 2005):

$$
V_{\mathrm{Rc}}=3.342\left(A_{s} f_{\mathrm{ck}}\right)^{1 / 3}\left(2 c d^{2 / 3}+1.5 \pi d^{5 / 3}\right) .
$$

When calculating the design $V_{\mathrm{Rd}, \mathrm{c}}$, the coefficients 6.684 and 3.342 should be divided by the reliability coefficient $\gamma_{c}$ of concrete.

Applying methodology of Kudzys and Kliukas (2010), the theoretical standard deviation of punching shear strength can be calculated according to the equation:

$$
\begin{aligned}
\sigma^{2} V_{\mathrm{R}}= & \left(\partial V_{\mathrm{R}} / \partial f_{\mathrm{ck}}\right)^{2} \sigma^{2} f_{\mathrm{ck}}+\left(\partial V_{\mathrm{R}} / \partial d\right)^{2} \sigma^{2} d+ \\
& \left(\partial V_{\mathrm{R}} / \partial A_{\mathrm{s}}\right)^{2} \sigma^{2} A_{\mathrm{s}},
\end{aligned}
$$

where: $\sigma^{2} f_{\mathrm{ck}}=\left(\delta f_{\mathrm{ck}}{ }^{*} f_{\mathrm{ck}}\right)^{2} ; \sigma^{2} d=\left(\delta d^{*} d\right)^{2} ; \sigma^{2} A_{\mathrm{s}}=$ $\left(\delta A_{\mathrm{s}} * A_{\mathrm{s}}\right)^{2}$.

If we equate the design acting force $V_{\mathrm{Ed}}$ to the design resistance force $V_{\mathrm{Rd}, \mathrm{c}},\left(V_{\mathrm{Ed}}=V_{\mathrm{Rd}, \mathrm{c}}\right)$ the reliability index $\beta$ can be calculated according to equation:

$$
\beta=\left(V_{\mathrm{Rm}}-\mu_{V \mathrm{E}}\right) /\left(\sigma^{2} V_{\mathrm{Rm}}+\sigma^{2} \mu_{V \mathrm{E}}\right)^{1 / 2},
$$

where: $V_{\mathrm{Rm}}$ - the average value of punching shear resistance of a slab; $\sigma^{2} V_{\mathrm{Rm}}$ - the average standard deviation of resistance values; $\mu_{V \mathrm{E}}$ - the total mean of construction effects; $\sigma^{2} \mu_{V \mathrm{E}}-$ the average standard deviation of effects.

The average value of punching shear resistance of a slab is calculated according to Eqn (13) or (14) and the standard square deviation of punching shear resistance according to Eqn (15) by changing $f_{\mathrm{ck}}$ into $f_{\mathrm{cm}}$. The values of the variation coefficient chosen for a theoretical research: for compressed concrete $\delta f_{c}=0.1, \delta f_{c}=0.15$ and $\delta f_{c}=0.2$, for the effective depth $\delta d=0.1$ and for the area of longitudinal reinforcement cross-section $\delta A_{\mathrm{s}}=0.05$ and $\delta A_{\mathrm{s}}=0.075$.

Different scientists (Nowak 1994; Ellingwood et al. 1980, 2004; Ellingwood 1981; Ellingwood, Rosowsky 1991; Ellingwood, Tekie 1999; CEB/fib Task Group 2001; Scott et al. 2003; Rosowsky 2001; Gulvanessian, 
Holicky 2005; Vainiūnas 2006; Kudzys, Kliukas 2010) investigated the dependences of reliability index $\beta$ of different building structures on different values of random factors. These authors suggest in order to calculate the $G$ mean $m_{\mathrm{G}}$ of the self-weight of structures $\mu_{V \mathrm{E}}$ to take $(1.0-0.07) G_{\mathrm{k}}$, its variation coefficient $\delta_{G}=0.07-00.15$; the mean $\mu_{\mathrm{Q}, 50}=(0.6-1.05) Q_{50, \mathrm{k}}$ of variable load $Q$ over the period of 50 years $Q_{50}$, its variation coefficient $\delta_{\mathrm{Q}, 50}=0.2-0.35$; the average mean wind load $W$ where $\mu_{\mathrm{W}}=(0.47-0.9) W_{\mathrm{k}}$, its variation coefficient $\delta_{W}=$ $0.15-0.37$; the average mean of snow load $S$ when $\mu_{\mathrm{S}}=0.82 S_{\mathrm{k}}$, its variation coefficient $\delta_{S}=0.26-0.5$.

In Lithuanian design codes (STR 2.05.03:2003 2003) the mean $m_{\mathrm{G}}$ and the standard deviation $s_{\mathrm{G}}$ of the load $G$ of the self-weight of the structure are received by applying the expressions: $m_{\mathrm{G}}=l G_{\mathrm{k}}$ and $s_{\mathrm{G}}=\delta_{G} m_{\mathrm{G}}$, here $G_{\mathrm{k}}$ - the characteristic value of the self-weight load, $l=1.0$, variation coefficient $\delta_{G}=0.1$. According to the same codes, the mean $\mu_{\mathrm{Q}, 50}$ of the variable load $Q$ over the period of 50 years $Q_{50}$ and the average standard deviation $\sigma_{\mathrm{Q}, 50}$ are calculated by applying expressions: $\mu_{\mathrm{Q}, 50}=Q_{\mathrm{k}}$, and $\sigma_{\mathrm{Q}, 50}=\delta_{Q} \mu_{\mathrm{Q}, 50}$, here $Q_{\mathrm{k}}$ - the characteristic value of variable loads $Q$ over the period of 50 years, and $\delta_{Q}=0.3$.
The characteristic load $V_{\mathrm{Ek}}$ of beamless floors usually consists of the self-weight of the structure $G_{\mathrm{k}}$ and the effective load $Q_{\mathrm{k}}: V_{\mathrm{Ek}}=G_{\mathrm{k}}+Q_{\mathrm{k}}$. Since the design value of effect in a general form is expressed by: $F_{\mathrm{d}}=\gamma_{\mathrm{f}} \psi F_{\mathrm{k}}$ and if we take the combination factor $\psi=1.0$ and partial coefficients of effect $\gamma_{\mathrm{fG}}=1.35$ and $\gamma_{\mathrm{fQ}}=1.5$ (EN 1990:2002 2002), the design punching shear force can be calculated according to the formula:

$$
V_{\mathrm{Ed}}=1.35 G_{\mathrm{k}}+1.5 Q_{\mathrm{k}}=V_{\mathrm{Rd}, \mathrm{c}} .
$$

By applying the recommendation of the code STR 2.05.05:2005 (2005), that $\mu_{V \mathrm{E}}=G_{\mathrm{k}}+Q_{\mathrm{k}}$ and $\sigma^{2} \mu_{V \mathrm{E}}$ and assuming the ratios of $G_{\mathrm{k}} / Q_{\mathrm{k}}=2, G_{\mathrm{k}} / Q_{\mathrm{k}}=1$ and $G_{\mathrm{k}} / Q_{\mathrm{k}}=0.5$, the calculations for these three combinations are made. Tables 2 and 3 and Figures 5-7 present the results of calculating the reliability index $\beta$ calculated according to EN 1992-1-1:2004 (2004) and STR 2.05.05:2005 (2005) by applying mentioned ratios $G_{\mathrm{k}} / Q_{\mathrm{k}}$ and different variation coefficients of independent variables $\left(f_{\text {ck }}, d, A_{\mathrm{s}}\right)$.

A theoretical research shows that only in case when the effective load is around $50 \%$ of the self-weight of the construction, i.e. $G_{\mathrm{k}} / Q_{\mathrm{k}}=2$ and if we take the minimal values of the variation coefficient: for compressive

Table 2. $\beta$ were calculated according to EN 1992-1-1:2004 (2004)

\begin{tabular}{|c|c|c|c|c|c|c|c|}
\hline \multirow{11}{*}{$\begin{array}{l}\delta d=0.1 \\
\delta A_{\mathrm{s}}=0.05\end{array}$} & \multirow[b]{2}{*}{$\delta_{\mathrm{fc}}$} & \multirow[b]{2}{*}{$G_{\mathrm{k}} / Q_{\mathrm{k}}$} & \multicolumn{5}{|c|}{$\rho(\%)$} \\
\hline & & & 0.449 & 0.718 & 1.00 & 1.50 & 1.90 \\
\hline & \multirow{3}{*}{0.1} & 2 & 3.861 & 3.939 & 3.884 & 4.014 & 4.036 \\
\hline & & 1 & 3.746 & 3.817 & 3.75 & 3.888 & 3.915 \\
\hline & & 0.5 & 3.6 & 3.667 & 3.638 & 3.766 & 3.771 \\
\hline & \multirow{3}{*}{0.15} & 2 & 3.741 & 3.812 & 3.761 & 3.885 & 3.905 \\
\hline & & 1 & 3.639 & 3.705 & 3.642 & 3.773 & 3.799 \\
\hline & & 0.5 & 3.506 & 3.569 & 3.542 & 3.664 & 3.668 \\
\hline & \multirow{3}{*}{0.2} & 2 & 3.587 & 3.656 & 3.606 & 3.723 & 3.742 \\
\hline & & 1 & 3.502 & 3.565 & 3.504 & 3.628 & 3.652 \\
\hline & & 0.5 & 3.384 & 3.445 & 3.419 & 3.533 & 3.538 \\
\hline \multirow{3}{*}{$\begin{array}{l}\delta f_{\mathrm{c}}=0.1 \\
\delta d=0.1\end{array}$} & \multirow{3}{*}{$\delta A_{\mathrm{S}}=0.075$} & 2 & 3.83 & 3.906 & 3.853 & 3.982 & 4.003 \\
\hline & & 1 & 3.719 & 3.788 & 3.723 & 3.859 & 3.885 \\
\hline & & 0.5 & 3.575 & 3.642 & 3.613 & 3.74 & 3.745 \\
\hline
\end{tabular}

Table 3. $\beta$ were calculated according to STR 2.05.05:2005 (2005)

\begin{tabular}{|c|c|c|c|c|c|c|c|}
\hline \multirow{8}{*}{$\begin{array}{l}\delta d=0.1 \\
\delta A_{\mathrm{s}}=0.05\end{array}$} & \multirow[b]{2}{*}{$\delta_{\mathrm{fc}}$} & \multirow[b]{2}{*}{$G_{\mathrm{k}} / Q_{\mathrm{k}}$} & \multicolumn{5}{|c|}{$\rho(\%)$} \\
\hline & & & 0.449 & 0.718 & 1.00 & 1.50 & 1.90 \\
\hline & \multirow{3}{*}{0.1} & 2 & 4.037 & 4.094 & 4.062 & 4.198 & 4.202 \\
\hline & & 1 & 3.889 & 3.945 & 3.917 & 4.054 & 4.057 \\
\hline & & 0.5 & 3.745 & 3.809 & 3.772 & 3.89 & 3.912 \\
\hline & \multirow{3}{*}{0.2} & 2 & 3.727 & 3.778 & 3.748 & 3.868 & 3.869 \\
\hline & & 1 & 3.617 & 3.666 & 3.64 & 3.765 & 3.762 \\
\hline & & 0.5 & 3.506 & 3.564 & 3.529 & 3.634 & 3.652 \\
\hline
\end{tabular}




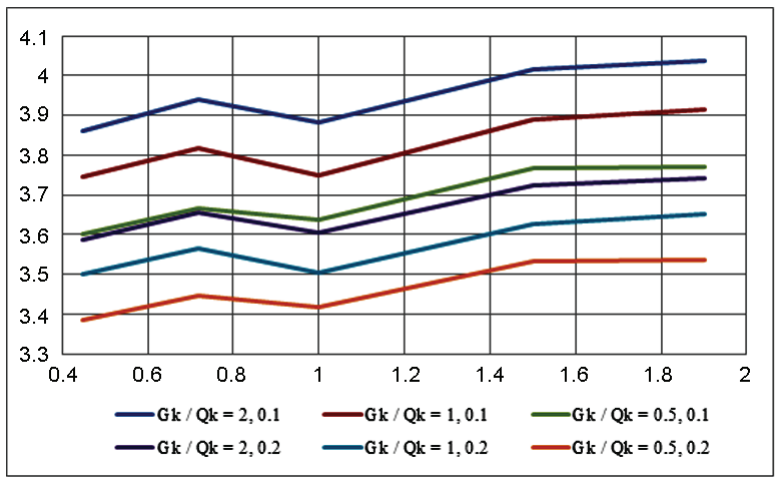

Fig. 5. Theoretical $\beta$ calculated according to EN 1992-1-1:2004 (2004) depending on the variation coefficients of $\rho(\%)$ and independent variables $\left(f_{\mathrm{ck}}, d, A_{\mathrm{s}}\right)$. The points of curves were calculated by taking $\delta d=0,1$ and $\delta A_{\mathrm{s}}=0.05$ for all curves, and were different by the ratio $G_{\mathrm{k}} / Q_{\mathrm{k}}\left(G_{\mathrm{k}} / Q_{\mathrm{k}}=2, G_{\mathrm{k}} / Q_{\mathrm{k}}=1\right.$ and $\left.G_{\mathrm{k}} / Q_{\mathrm{k}}=0.5\right)$ also $\delta f_{c}\left(\delta f_{c}=0.1\right.$ and $\left.\delta f_{c}=0.2\right)$

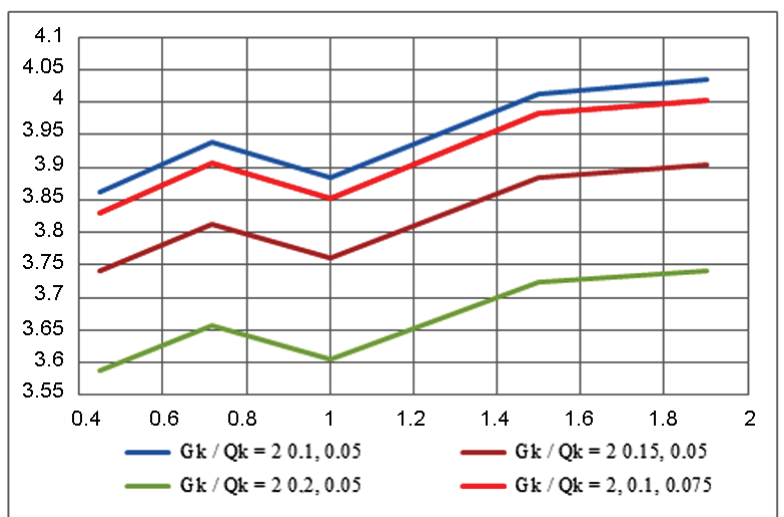

Fig. 6. Theoretical values of $\beta$ calculated according to EN 19921-1:2004 (2004) depending on the variation coefficients of $\rho(\%)$ and independent variables $\left(f_{\mathrm{ck}}, d, A_{\mathrm{s}}\right)$. The points of curves were calculated by taking $G_{\mathrm{k}} / Q_{\mathrm{k}}=2, \delta d=0.1$ for all curves, and different $\delta f_{c}\left(\delta f_{c}=0.1, \delta f_{c}=0.15\right.$ and $\left.\delta f_{c}=0.2\right)$ also $\delta A \mathrm{~s}(\delta A \mathrm{~s}=$ 0.05 and $\left.\delta A_{\mathrm{s}}=0.075\right)$

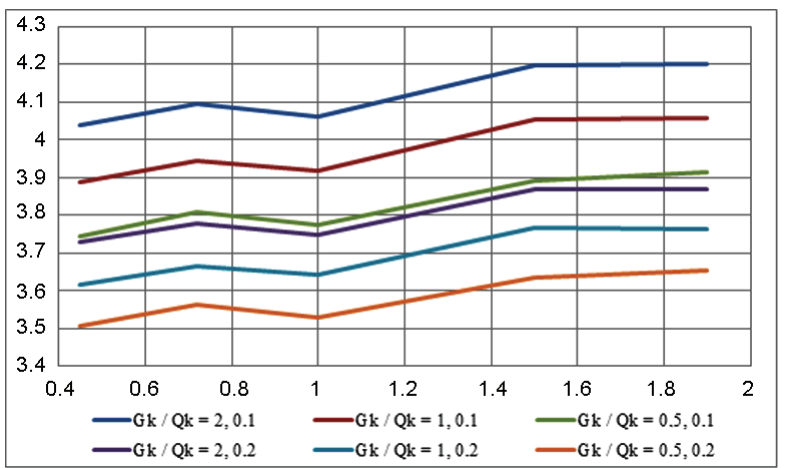

Fig. 7. Theoretical $\beta$ calculated according to STR 2.05.05:2005 (2005) depending on the variation coefficients of $\rho(\%)$ and independent variables $\left(f_{\mathrm{ck}}, d, A_{\mathrm{s}}\right)$. The points of curves were calculated by taking $\delta d=0.1$ and $\delta A_{\mathrm{s}}=0.05$ for all curves, and they differ by the ratio of $G_{\mathrm{k}} / Q_{\mathrm{k}}\left(G_{\mathrm{k}} / Q_{\mathrm{k}}=2, G_{\mathrm{k}} / Q_{\mathrm{k}}=1\right.$ and $\left.G_{\mathrm{k}} / Q_{\mathrm{k}}=0.5\right)$, also $\delta f_{c}\left(\delta f_{c}=0.1\right.$ and $\left.\delta f_{c}=0.2\right)$ strength of concrete $\delta f_{c}=0.1$, for the effective depth $\delta d=0.1$ and for the area of longitudinal reinforcement cross-section $\delta A_{\mathrm{s}}=0.05$ or $\delta \mathrm{A}_{\mathrm{s}}=0.075$, the reliability index $\beta$ of the analyzed slabs calculated according to EN 1992-1-1:2004 (2004) ranges from 3.83 to 4.036 . It is bigger than the lowest reliability index value -3.8 (Table 2 and Figs 5, 6) recommended in EN 1990:2002 (2002) for the critical state of RC2 reliability class structures. The calculated reliability index $\beta$ is greater than or close to 3.8, when $G_{\mathrm{k}} / Q_{\mathrm{k}}=1$, and $\delta f_{\mathrm{c}}=0.1, \delta A_{\mathrm{s}}=0.05$ or $\delta A_{\mathrm{s}}=0.075$, and also when $G_{\mathrm{k}} / Q_{\mathrm{k}}=2$ and $\delta f_{c}=0.15$. If manufacturing control quality is worse or the requirements of manufacturing technology are not fulfilled, variation of material strength increases, which is especially typical of concrete compressive strength as a result of which the value of the variation coefficient of concrete strength may increase even up to $\delta f_{\mathrm{c}}=0.2$. When $\delta f_{\mathrm{c}}=0.2$ or $G_{\mathrm{k}} / Q_{\mathrm{k}}=0.5$ in all cases, $\beta$ is less than 3.8 (Table 2 and Figs 5,6$)$. The reliability index $\beta$ calculated according to STR 2.05.05:2005 (2005) taking that $\delta f_{c}=0.1, \delta d=0.1$ and $\delta A_{\mathrm{s}}=0.05$ also $G_{\mathrm{k}} / Q_{\mathrm{k}}=2$ and $G_{\mathrm{k}} / Q_{\mathrm{k}}=1$ is higher than 3.8, and when $G_{\mathrm{k}} / Q_{\mathrm{k}}=0.5$, it is higher than or close to 3.8. Even when $\delta f_{c}=0.2$ and $G_{\mathrm{k}} / Q_{\mathrm{k}}=2, \beta$ is higher or close to 3.8. Only when $\delta f_{c}=0.2$ and $G_{\mathrm{k}} / Q_{\mathrm{k}}=0.5$, the index of reliability $\beta$ does not reach the lowest value of the reliability index (Table 3 and Fig. 7).

According to Eqn (2), the punching shear strength depend on $A_{s}, f_{c m}$ and $d$. The equivalent punching shear strength value from test results can be obtained. While calculating equivalent value leaner approximation $A_{s}, f_{c m}$ and $d$, the power multipliers $\lambda$ were calculated:

$$
\lambda=\left(A_{\mathrm{s}} f_{\mathrm{cm}} / d\right)^{1 / 3} .
$$

Using Mathcad software, the leaner approximation was obtained:

$$
V_{\mathrm{Rem}}=-0.351+1.131 \lambda ; \sigma^{2} V_{\mathrm{Re}}=1.127 * 10^{-3} .
$$

Here $V_{\text {Rem }}$ is the equivalent punching shear strength value.

The coefficient $\lambda$ not clearly and accurate represents the influence of reinforcement ratio, concrete strength and effective depth because of the small number of tests (Table 1).

When experimental slabs are manufactured in a laboratory, the quality of specimens is high. As a result, the standard deviation of specimens' strength is much smaller, and, in this way, the values of the reliability index $\beta$ are much higher ranging from 6.028 to 8.645 (Table 4 and Fig. 8).

Table 4. Experimental values of $\beta$

\begin{tabular}{l|c|l|l|l|l|l}
\hline \multirow{2}{*}{$\delta$} & & \multicolumn{5}{|c}{$\rho(\%)$} \\
\cline { 3 - 7 } & $G_{\mathrm{k}} / Q_{\mathrm{k}}=0.1$ & 0.449 & 0.718 & 1.00 & 1.50 & 1.90 \\
\cline { 2 - 7 } & 2 & 6.465 & 6.374 & 7.169 & 7.446 & 8.645 \\
\cline { 2 - 7 }$\delta d=0.1$ & 1 & 6.271 & 6.15 & 6.807 & 7.113 & 8.208 \\
\cline { 2 - 7 }$\delta \mathrm{A}_{\mathrm{s}}=0.05$ & 0.5 & 6.028 & 5.899 & 6.485 & 6.803 & 8.208 \\
\hline
\end{tabular}




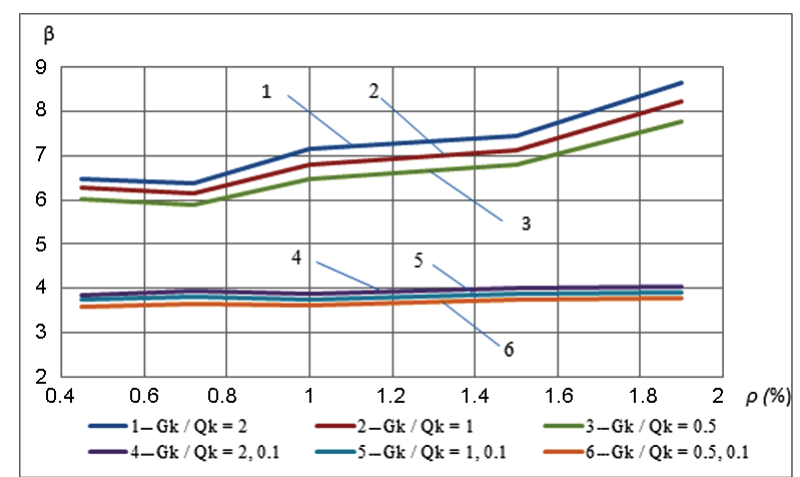

Fig. 8. The index of reliability $\beta$ calculated according to EN 1992-1-1:2004 (2004) depending on $\rho(\%)$ and similar values of variation coefficients $\delta f_{c}=0.1, \delta d=0.1$ and $\delta A_{\mathrm{s}}=0.5$ of independent variables $\left(f_{\mathrm{ck}}, d, A_{\mathrm{s}}\right)$ but different ratios of $G_{\mathrm{k}} / Q_{\mathrm{k}}$ : $\left(G_{\mathrm{k}} / Q_{\mathrm{k}}=2, G_{\mathrm{k}} / Q_{\mathrm{k}}=1\right.$ also $\left.G_{\mathrm{k}} / Q_{\mathrm{k}}=0.5\right) .1,2,3$ - experimental curves; 4, 5, 6 - theoretical curves

Research shows that the index $\beta$ of reliability increases when the ratio of longitudinal reinforcement $\rho$ increases (Tables 2-4 and Figs 5-7).

\section{Analysis of results}

As shown in Figures 5-8, the theoretical values of the reliability index $\beta$ are significantly different and this difference depends on many parameters. It is obvious from Eqn (16) that different parameters influence the differences of these results: both the loading ratio $G_{\mathrm{k}} / Q_{\mathrm{k}}$ present in the function of effects, as well as the geometrical and strength parameters of the slab, present in the resistance function $-A_{\mathrm{s}}, d, f_{c}, c$. Therefore, the resistance function $g$ (Eqn (9)) is a function with several variables whose arguments are random values distributed according to a certain law and described by a certain average and a square deviation (or variation coefficient). Having calculated the standard deviation of function $g$ and having expressed in percentage the significance of each argument, it is possible to make conclusions about the influence of relevant $g$ function arguments considering their standard deviations both on the reliability index $\beta$ as well as the resistance function itself.

Assuming that $\delta f_{c}=0.1, \delta d=0.1, \delta A_{\mathrm{s}}=0.1, \delta c=$ $0.1, \delta G=0.1, \delta Q=0.3$ and having done the mentioned calculations for all slabs described in Table 1, certain tendencies were noticed (here $\delta c$ is the variation coefficient of the column cross-section dimension). Figure 9 presents theoretical dependences of the standard deviation $\sigma^{2} V_{\mathrm{Rm}}$ of resistance and the standard deviation $\sigma^{2} \mu_{V \mathrm{E}}$ of effects depending on the ratio $G_{\mathrm{k}} / Q_{\mathrm{k}}$ (in the given case the slab PP-20.1). When $G_{\mathrm{k}} / Q_{\mathrm{k}}=2$, the standard deviation of resistance has more influence (58\%), in comparison with the standard deviations of effects $(42 \%)$. When $G_{\mathrm{k}} / Q_{\mathrm{k}}=1$, the standard deviation of resistance becomes less important in comparison with the standard deviation of effects $(44 \%$ and $56 \%)$. In the meantime, when $G_{\mathrm{k}} / Q_{\mathrm{k}}=0,5$, the standard deviation of effects has a much

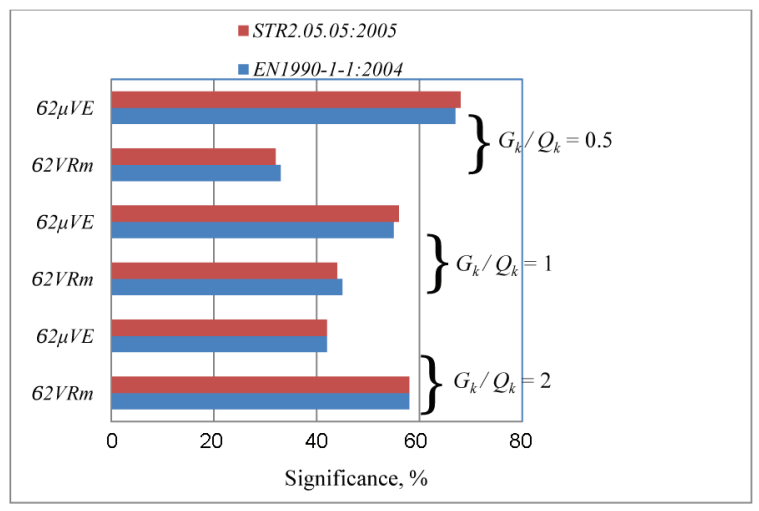

Fig. 9. Theoretical significances of resistance $\sigma^{2} V_{\mathrm{Rm}}(\%)$ and effects $\sigma^{2} \mu_{V \mathrm{E}}$ depending on the ratio of $G_{\mathrm{k}} / Q_{\mathrm{k}}$

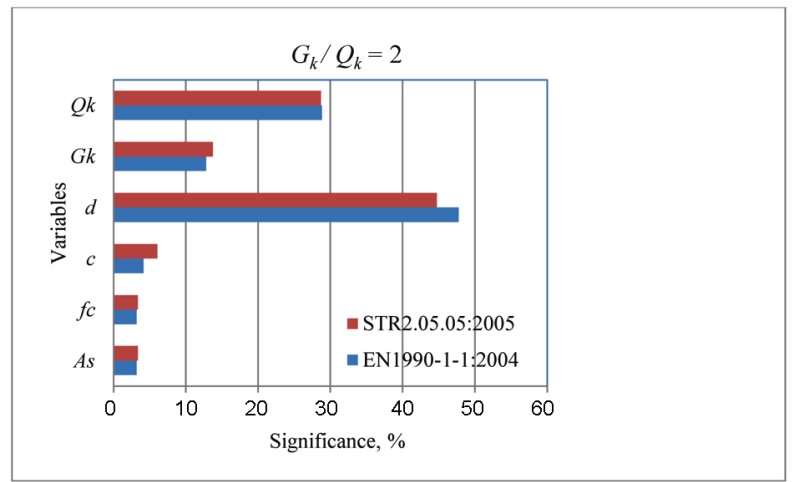

Fig. 10. Theoretical significances (\%) of standard deviations of independent variables calculated according to STR 2.05.05:2005 (2005) and EN 1990:2002 (2002), when $G_{\mathrm{k}} / Q_{\mathrm{k}}=2$

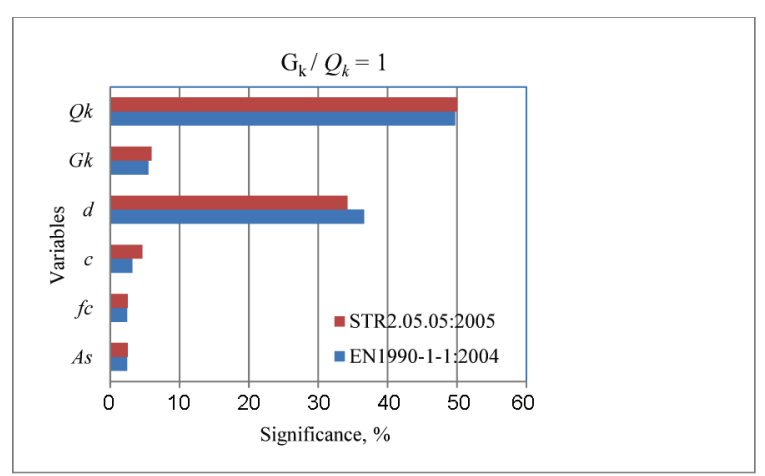

Fig. 11. Theoretical significances (\%) of standard deviations of independent variables calculated according to STR 2.05.05:2005 (2005) and EN 1990:2002 (2002), when $G_{\mathrm{k}} / Q_{\mathrm{k}}=1$

more significant influence (68\%), and the influence of the standard deviation of resistance is no longer so significant $(32 \%)$.

It is also meaningful to compare the influence of independent random variables: $Q_{\mathrm{k}}, G_{\mathrm{k}}, d, f_{c}$, and the influence of $A_{s}$, on the value of function $g$ for the standard deviation $\sigma_{g}$.

Figures $10-12$ show the relative significance of variables for the slab PP-20.1, calculated according to STR 2.05.05:2005 (2005) EN 1990:2002 (2002) depend- 


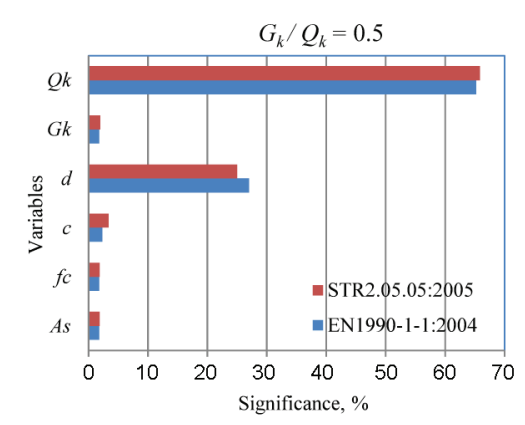

Fig. 12. Theoretical significances (\%) of standard deviations of independent variables calculated according to STR 2.05.05:2005 (2005) and EN 1990:2002 (2002), when $G_{\mathrm{k}} / Q_{\mathrm{k}}=0.5$

ing on the ratio of $G_{\mathrm{k}} / Q_{\mathrm{k}}$. As it can be seen from the graph in Figure 9, when the ratio is $G_{\mathrm{k}} / Q_{\mathrm{k}}=2$, the standard deviation $\left.\left(\partial V_{\mathrm{R}} / \partial d\right)^{2} \sigma^{2} d\right)$ of the effective depth $d$ of the slab becomes the most significant, whereas the standard deviation of variable load $Q_{\mathrm{k}}$ is the second in importance. When the ratio $G_{\mathrm{k}} / Q_{\mathrm{k}}$ is 1 or 0.5 , the most significant is the standard deviation of the changing load $Q_{\mathrm{k}}(50 \%$ and $65 \%$ respectively), the second in importance is the deviation of the effective depth $d$ of a slab (37\% and 27\%, respectively) and other deviations of factors practically become insignificant.

It should be noted that while calculating the mentioned significances according to different design codes (STR 2.05.05:2005 (2005) and EN 1990:2002 (2002)) the results are not different - they vary within the range of only a few percent.

\section{Acknowledgements}

This work was funded by the European Social Fund Agency, Project No. VP1-3.1-MES-10-V-02-006.

\section{Conclusions}

1. Research shows that when the effective load makes around $50 \%$ of the self-weight of the construction, i.e. $G_{\mathrm{k}} / Q_{\mathrm{k}}=2$ and when we take the minimal values of the variation coefficient: for the compressed concrete $\delta f_{c}=0.1$, for the effective depth $\delta d=0.1$ and for the area of the longitudinal reinforcement cross-section $\delta A_{\mathrm{s}}=0.05$ or $\delta A_{\mathrm{S}}=0.075$, the reliability index $\beta$ of the analyzed slabs calculated according to EN 1992-1-1:2004 (2004) is higher than the smallest value of the reliability index 3.8 recommended in EN 1990:2002 (2002) for the critical state of the RC2 construction reliability class. The calculated reliability index $\beta$ is higher or close to 3.8 , when $G_{\mathrm{k}} / Q_{\mathrm{k}}=1$, and $\delta f_{\mathrm{c}}=0.1, \delta A_{\mathrm{s}}=0.05$ or $\delta A_{\mathrm{s}}=0.075$, also when $G_{\mathrm{k}} / Q_{\mathrm{k}}=2$ and $\delta f_{c}=0.15$. When $\delta f_{\mathrm{c}}=0.2$ or $G_{\mathrm{k}} / Q_{\mathrm{k}}=0.5$, in all cases $\beta$ is less than 3.8.

2 . The reliability index $\beta$ calculated according to STR 2.05.05:2005 (2005) assuming that $\delta f_{c}$ $=0.1, \delta d=0.1$ and $\delta A_{\mathrm{s}}=0.05$ as well as $G_{\mathrm{k}} / Q_{\mathrm{k}}=2$ and $G_{\mathrm{k}} / Q_{\mathrm{k}}=1$ is higher than 3.8, and if $G_{\mathrm{k}} / Q_{\mathrm{k}}=0.5$ higher or close to 3.8. Even when $\delta f_{c}=0.2$ and $G_{\mathrm{k}} / Q_{\mathrm{k}}=2, \beta$ is higher or close to 3.8 . Only when $\delta f_{c}=0.2$ and $G_{\mathrm{k}} / Q_{\mathrm{k}}=0.5$, the reliability index $\beta$ does not meet the allowed value of the reliability index.

3 . When experimental slabs are produced in a laboratory, a high quality of specimens is received. As a consequence, the standard deviation of specimens' strength is much smaller and at the same time the values of the reliability index $\beta$ are much higher and vary from 6.028 to 8.645 .

4. Theoretical and experimental research shows that the reliability index $\beta$ increases if the ratio of longitudinal reinforcement $\rho$ increases.

5. Analysis of the results shows that the most important factors calculating reliability index according to STR 2.05.05:2005 (2005) and EN 1990:2002 (2002) are the ratio of $G_{\mathrm{k}} / Q_{\mathrm{k}}$ and the effective depth of the slab.

6. Depending on the ratio of the $G_{\mathrm{k}} / Q_{\mathrm{k}}$, the influence of standard deviation of effects and resistance is different: when the ratio of $G_{\mathrm{k}} / Q_{\mathrm{k}}$ increases, resistance function arguments $\left(d, c, A_{s}, f_{c}\right)$ of a slab have a more significant influence; when the $G_{\mathrm{k}} / Q_{\mathrm{k}}$ ratio decreases, the influence is opposite, i.e. load $Q_{\mathrm{k}}$ becomes the most important factor.

\section{References}

ACI 318-05. Building code requirements for structural concrete. American Concrete Institute, Farmington Hills, Michigan, 2005. $430 \mathrm{p}$.

Albrecht, U. 2002. Design of flat slabs for punching - European and North American practices, Cement \& Concrete Composites 24(6): 531-538.

http://dx.doi.org/10.1016/S0958-9465(01)00069-5

AS 3600-2009. Australian standard for concrete structures. Standards Australia, 2009. 198 p.

BS 8110. Structural use of concrete, Part 1 - code of practice for design and construction. London: British Standards Institution, 1997. $172 \mathrm{p}$.

Carvalho, A. L.; Melo, G. S.; Gomes, R. B.; Regan, P. E. 2011. Punching shear in post-tensioned flat slabs with stud rail shear reinforcement, ACI Structural Journal 108(5): 523531.

CEB/fib Task Group. 2001. Punching of structural concrete technical report. Bulletin 12. 307 p.

CSA-A23.3-04. Design of concrete structures for buildings. Ontario, Canada: Canadian Standards Association, 2004. $258 \mathrm{p}$.

DIN 1045-1(07/02). Tragwerke aus Beton, Stahlbetonund Spannbeton, Teil 1, Bemessung und Konstruktion. Berlin, September 2002. 58 p.

Ellingwood, B. R. 1981. Wind and snow load statistics for probabilistic design, Journal of Structural Division 107(7): 1345-1349.

Ellingwood, B. R.; Rosowsky, D. V. 1991. Duration of load effects in LRFD for wood construction, Journal of Structural Engineering 117(2): 584-599.

http://dx.doi.org/10.1061/(ASCE)0733-9445(1991)117:2(584)

Ellingwood, B. R.; Rosowsky, D. V.; Li, Y.; Kim, J. 2004. Fragility assessment of light-frame wood construction subjected to wind and earthquake hazards, Journal of Structural Engineering 130(12): 1921-1930. http://dx.doi. org/10.1061/(ASCE)0733-9445(2004)130:12(1921) 
Ellingwood, B. R.; Tekie, P. B. 1999. Wind load statistics for probability-based structural design, Journal of Structural Engineering 125(4): 453-463.

http://dx.doi.org/10.1061/(ASCE)0733-9445(1999)125:4(453)

Ellingwood, B.; Galambos, T. V.; MacGregor, J. G.; Cornell, C. A. 1980. Development of a probability based load criterion for American National Standard A58 - building code requirements for minimum design loads in buildings and other structures. Washington: National Bureau of Standards. 228 p.

EN 1990:2002. Eurocode - basis of structural design. Brussels: European Committee for Standardization, 2002. 87 p.

EN 1992-1-1:2004. Eurocode 2: design of concrete structures part 1: general rules and rules for buildings. Brussels: European Committee for Standardization, 2004. 225 p.

Faria, D. V.; Inácio, M. M. G.; Lúcio, V.; Ramos, A. P. 2012. Punching of strengthened concrete flat slabs - experimental analysis and comparison with codes, Structural Engineering International 22(2): 202-214. http://dx.doi.org/10.2749/101686612X13291382990921

Gardner, N. J. 2011. Verification of punching shear provisions for reinforced concrete flat slabs, ACI Structural Journal 108(5): 572-580.

Głodkowska, W.; Kobaka, J. 2012. The model of brittle matrix composites for distribution of steel fibres, Journal of Civil Engineering and Management 18(1): 145-150. http://dx.doi.org/10.3846/13923730.2012.657405

Guandalini, S.; Burdet, O. L.; Muttoni, A. 2009. Punching tests of labs with low reinforcement ratios, ACI Structural Journal 106(1): 87-95.

Gulvanessian, H.; Holicky, M. 2005. Eurocodes: using reliability analysis to combine action effects, in Proceedings of the Institution of Civil Engineers Structures \& Buildings, August 2005, Issue SB4: 243-252.

He, X-h.; Yu, X-d.; Chen, Z-q. 2012. Nonstationarity analysis in wind-rain-induced vibration of stay cables, Journal of Civil Engineering and Management 18(6): 821-827. http://dx.doi.org/10.3846/13923730.2012.720933

JCSS 2000 Probabilistic model code: Part 1 - Basis on design. Joint Committee on Structural Safety. 64 p.

Kong, D.; Lu, S.; Frantzich, H.; Lo, S. M. 2013. A method for linking safety factor to the target probability of failure in fire safety engineering, Journal of Civil Engineering and Management 19(Supplement 1): S212-S221. http://dx.doi.org/10.3846/13923730.2013.802718

Kudzys, A.; Kliukas, R. 2010. Probability-based design of spun concrete beam-columns, Journal of Civil Engineering and Management 16(4): 451-461.

http://dx.doi.org/10.3846/jcem.2010.51

Matthys, S.; Taerwe, L. 2000. Concrete slabs reinforced with FRP grids. II: Punching Resistance, Journal of Composites for Construction 4(3): 154-161.

http://dx.doi.org/10.1061/(ASCE)1090-0268(2000)4:3(154)
Menétrey, P. 2002. Synthesis of punching failure in reinforced concrete, Cement and Concrete Composites 24(6): 497-507. http://dx.doi.org/10.1016/S0958-9465(01)00066-X

Model Code 2010. Finaldraft, Volume 1, fib Bulletin No. 65. 350 p.

Muttoni, A. 2008. Punching shear strength of reinforced concrete slabs without transverse reinforcement, ACI Structural Journal 105(4): 440-450.

Ngo, D. T. 2001. Punching shear resistance of high-strength concrete slabs, Electronic Journal of Structural Engineering 1: 52-59.

Nowak, A. S. 1994. Load model for bridge design code, Canadian Journal of Civil Engineering 21(1): 36-49. http://dx.doi.org/10.1139/194-004

Rizk, E.; Marzouk, H.; Hussein, A. 2011. Punching shear of thick plates with and without shear reinforcement, $A C I$ Structural Journal 108(5): 581-591.

Rosowsky, D. V. 2001. Studies on probability-based design for residential vonstruction. Washington DC, USA. 35 p.

Ruiz, M. F.; Muttoni, A. 2009. Applications of critical shear crack theory to punching of reinforced concrete slabs with transverse reinforcement, ACI Structural Journal 106(4): 485-494.

Šakinis, D.; Vainiūnas, P. 2009. Influence of longitudinal reinforcement on the punching shear resistance of reinforced concrete slabs, Statybines konstrukcijos ir technologijos [Engineering Structures and Technologies] 1(2): 73-79 (in Lithuanian).

Scott, B.; Kim, B. J.; Salgado, R. 2003. Assessment of current load factors for use in geotechnical load and resistance factor design, Journal of Geotechnical and Geoenvironmental Engineering 129(4): 287-295.

http://dx.doi.org/10.1061/(ASCE)1090-0241(2003)129:4(287)

SNIP 2.03.01-84. Concrete and reinforced concrete structures. Moscow: STIP Gosstroja SSSR, 1985. 79 p. (in Russian).

Soubra, A.-H.; Massih, D. S.; Abdel, Y. 2010. Probabilistic analysis and design at the ultimate limit state of obliquely loaded strip footings, Géotechnique 60(4): 275-285. http://dx.doi.org/10.1680/geot.7.00031

STR 2.05.03:2003. Basis of structural design. Vilnius, 2003 (in Lithuanian).

STR 2.05.05:2005. Design of concrete and reinforced concrete structures. Vilnius, 2005 (in Lithuanian).

Theodorakopoulos, D. D.; Swamy, R. N. 2002. Ultimate punching shear strength analysis of slab-column connections, Cement and Concrete Composites 24(6): 509-521. http://dx.doi.org/10.1016/S0958-9465(01)00067-1

Vainiūnas, P. 2006. Analysis of calculation of punching strength of RC slabs according to the design codes, Technological and Economic Development of Economy 12(2): 84-90 (in Lithuanian).

Zabulionis, D.; Sakinis, D.; Vainiūnas, P. 2006. Statistical analysis of design codes calculation methods for punching shear resistance in column-to-slab connections, Journal of Civil Engineering and Management 12(3): 205-213.

Povilas VAINIŪNAS. Doctor, Professor of Reinforced Concrete and Masonry Structures, Vilnius, Lithuania. PhD (1970) from Kaunas Polytechnic Institute (presently Kaunas Technological University). Chairman of national group of International Association for Bridge and Structural Engineering (IABSE). Former vicepresident (1992-95) and board member (since 1995) of Association of European Civil Engineering Faculties (AECEF). Chairman of scientific committee of biennial intern. conference "Modern building materials, structures and techniques" held at VGTU, Lithuania. Author and coauthor of over 70 research papers. Research interests: mechanics of reinforced concrete, theory of durability and reliability, design of buildings, development of territory planning and building code system of Lithuania and real estate assessment.

Remigijus ŠALNA. Assoc. Prof. of Reinforced Concrete and Masonry Structures, Vilnius Gediminas Technical University. PhD (2008) of Civil Engineering from Vilnius Gediminas Technical University. Research interests: mechanics of reinforced concrete, punching shear strength, steel fiber reinforced concrete, probability of building structures.

Dainius ŠAKINIS. MSc (CE), PhD student from 2003-2007, assistant at the Dept. of Reinforced Concrete and Masonry Structures at Vilnius Gediminas Technical University, Vilnius, Lithuania. Research interests: mechanics of reinforced concrete, design of buildings. 